\title{
Christliches Ägypten in der spätantiken Zeit
}

\author{
Akten der 2. Tübinger Tagung zum Christlichen Orient (7.-8. Dezember 2007) \\ Hrsg. v. Dmitrij Bumazhnov
}

Christliches Ägypten in der spätantiken Zeit

Herausgegeben von DMITRIJ BUMAZHNO

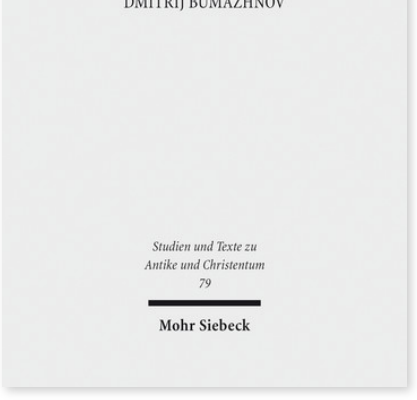

2013. XI, 355 Seiten. STAC 79

ISBN 978-3-16-152778-4 DOI 10.1628/978-3-16-152778-4 eBook PDF 104,00 €

ISBN 978-3-16-152777-7 fadengeheftete Broschur 104,00€
In diesem Band werden die, um einige Aufsätze ergänzten, Beiträge der 2. Tübinger Tagung zum Christlichen Orient im Jahr 2007 präsentiert, die den Zeitraum vom 3. bis zum 6. Jh. n.Chr. abdecken. Die Beiträge behandeln das koptische Proverbienbuch, die apokryphen Evangelien in koptischer Sprache und speziell das Thomasevangelium, sowie das frühe Mönchtum in Ägypten und dessen Verbindungen zum heidnischen Schrifttum (die antike Vorgeschichte des »Mittagsdämons« und die plotinische Reminiszenzen in einem Werk des Paulus von Tamma). Außerdem werden die Textgeschichte der Pachomiosviten, die Traktate Didymos des Blinden »Über den Heiligen Geist« und »De sectis« des Abbas Theodor und christlich-ägyptische Ikonographie und Ikonologie am Beispiel der Maiestas-Darstellungen in den koptischen Klöstern untersucht. Der Band enthält außerdem zwei koptische Textpublikationen: Zwei Fragmente Schenutes und die sahidische und bohairische Fassung des Testamentes Isaaks.

Inhaltsübersicht

\section{Biblisches}

Frank Feder: Die koptischen Versionen des Proverbienbuches

\section{Apokrypha und Verwandtes}

Jan Dochhorn: Mythen von der Einsetzung des Erzengels Michaels in der koptischen Literatur - Emmanouela Grypeou: Höllenreisen und engelgleiches Leben: Die Rezeption von apokalyptischen Traditionen in der koptisch-monastischen Literatur - Peter Nagel: Der Beitrag der Koptologie zur Wiedergewinnung und Erforschung der apokryphen Evangelien - Uwe-Karsten Plisch: EvThom 29 als Exzerpt ein Blick in die Entstehungsgeschichte des Thomasevangeliums - Alexander Toepel: »Was ihr verabscheut, das tut nicht.« Ethik im Thomasevangelium und bei Epikur

\section{Jahrhundert}

Pablo Argárate: Zwischen Origenes, Athanasius und Kyrill: ein weiteres Kapitel der alexandrinischen Pneumatologie. Das Traktat 'Über den Heiligen Geist' des Didymos - Dmitrij Bumazhnov: Eine Plotinreminiszenz bei dem hl. Paulus von Tamma? Zum Traditionsproblem im frühen ägyptischen Christentum - Johannes Grossmann: Neue Beobachtungen zur arabischen Göttinger Pachomiosvita im Vergleich mit den koptischen und griechischen Fassungen nebst einem Anhang zum Pachomiosmaterial der arabischen Handschriften des Sinai - Irmgard Männlein-Robert: Vom Wald in die Wüste: Der Mittagsdämon in der Spätantike

\section{5.-6. Jahrhundert}

Hans-Joachim Cristea: Schenute gegen ein falsches Sündenbewusstsein. Paris BNF copte 1302 ff. 110-111 (= DS 241/242 + 247/248) - Benjamin Gleede: Der Traktat »De sectis« des Abbas Theodor. Eine unvollendete Handreichung zur Widerlegung

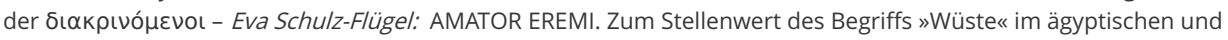
europäischen Mönchtum

Ikonographie und Ikonologie

Bärbe/ Dümler: Bilder in der Wüste. Fragen zu Funktion und Deutung von Maiestas-Darstellungen in ägyptischen Klöstern

Anhang. Textpublikation

Jan Dochhorn: Das Testament Isaaks nach dem sahidischen und dem bohairischen Textzeugen. Eine synoptische Übersicht mit kritischen Anmerkungen

Dmitrij Bumazhnov Geboren 1967; Studium der Klassischen Philologie an der Universität St. Petersburg; 2001 Promotion in "Sprachen und Kulturen des Christlichen Orients« Tübingen; 2008 Habilitation für das gleiche Fach in Tübingen; seit 2011 Mitglied des Forschungszentrums EDRIS, Göttingen.

Jetzt bestellen:

https://mohrsiebeck.com/buch/christliches-aegypten-in-der-spaetantiken-zeit-9783161527784?no_cache=1 order@mohrsiebeck.com

Telefon: $+49(0) 7071-923-17$

Telefax: $+49(0) 7071-51104$ 